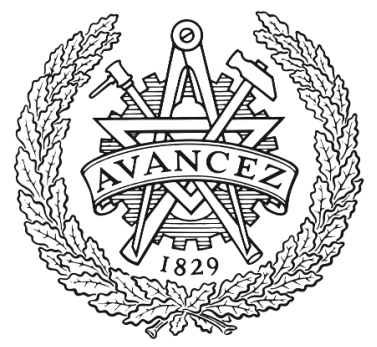

CHALMERS

UNIVERSITY OF TECHNOLOGY

\title{
A Slot Array Antenna with Single-Layered Corporate-Feed based on Ridge Gap Waveguide in the 60-GHz Band
}

Downloaded from: https://research.chalmers.se, 2023-04-26 08:53 UTC

Citation for the original published paper (version of record):

Liu, J., Vosoogh, A., Uz Zaman, A. et al (2019). A Slot Array Antenna with Single-Layered Corporate-Feed based on Ridge Gap Waveguide in the 60-GHz Band. IEEE Transactions on Antennas and Propagation, 67(3): 1650-1658.

http://dx.doi.org/10.1109/TAP.2018.2888730

N.B. When citing this work, cite the original published paper.

(O2019 IEEE. Personal use of this material is permitted.

However, permission to reprint/republish this material for advertising or promotional purposes 


\title{
A Slot Array Antenna with Single-Layered Corporate-Feed based on Ridge Gap Waveguide in the $60-\mathrm{GHz}$ Band
}

\author{
Jinlin Liu, Member, IEEE, Abbas Vosoogh, Student Member, IEEE, Ashraf Uz Zaman, Member, IEEE, \\ and Jian Yang, Senior Member, IEEE
}

\begin{abstract}
This paper presents an $8 \times 8$-element slot array antenna with single-layered corporate-feed based on the ridge gap waveguide technology in the $60-\mathrm{GHz}$ band. As is wellknown, a corporate-feed slot array antenna usually has backed cavities to increase the bandwidth and provide a space for its distribution network, and therefore three layers in total: one layer for radiating slots and two layers for feed network with one layer of back cavities and one of power dividers. The antenna in this work is designed by utilizing only two separate metallic layers - a corporate-feed network layer and a radiating slot layer. Compared with the conventional three-layered slot array antennas, the proposed antenna avoids the utilization of the backed cavity layer so that its complexity and manufacture cost decrease. In order to solve the problem of the narrow bandwidth caused by taking away the backed cavities we utilize doubleridged radiating slots instead of the conventional rectangular ones. A compact transition power divider from standard waveguide WR-15 to the ridge gap waveguide is introduced to excite the proposed array antenna. The $8 \times 8$-element slot array antenna has been fabricated by computerized numerical control machining technique. The measured results demonstrate that the $-10 \mathrm{~dB}$ reflection coefficient has around $17 \%$ bandwidth covering 56.5 $67 \mathrm{GHz}$ frequency range, and the measured gain is better than $26 \mathrm{dBi}$ with more than $70 \%$ antenna efficiency over 58 - $66 \mathrm{GHz}$.
\end{abstract}

Index Terms-Double-layered slot array, ridge gap waveguide, single-layered corporate-feed network, $60-\mathrm{GHz}$ frequency band.

\section{INTRODUCTION}

Recently, the current saturation of spectrum at microwave frequencies causes new attention to the millimeter waves (mmWs). Hence, the unlicensed $60-\mathrm{GHz}$ band (from 57 to $66 \mathrm{GHz}$ ) has a very strong potential for high data rates wireless communications [1]-[2]. However, the communication distance at $60-\mathrm{GHz}$ is strongly affected by atmospheric absorption [3]. Thereby, an antenna with high-gain and wideband is theoretically required for such kind of point-to-point wireless systems. The reflector antenna is normally a conventional choice. Nevertheless, thin planar slot array antennas are more desirable in the $60-\mathrm{GHz}$ frequency band due to its high efficiency and thin profile. A high-gain high-efficiency corporate-feed slot array antenna based on conventional hollow waveguide technology at $60-\mathrm{GHz}$ has been achieved in [4]. However, its fabrication is complicated and the corresponding

The authors are with Department of Electrical Engineering, Chalmers University of Technology, Gothenburg, Sweden(e-mails: jinlin.liu@ chalmers.se). cost is high. One traditional technology, patch array, has higher dielectric loss so that it is almost impossible to realize the high efficiency planar array in mmWs [5]. Another popular technology to mmWs is the substrate integrated waveguide (SIW). Nevertheless, its dielectric loss becomes problematically significant if it is applied for designing large high-gain array antennas in the 60-GHz band [6]-[7].

The gap waveguide is a new technology recently introduced in [8]-[9]. Theoretically, this new waveguide consists of two parallel plates, a top plate of perfect electric conductor (PEC) and a bottom plate of perfect magnetic conductor (PMC). If the air gap between the parallel plates is smaller than quarterwavelength, there is no propagating wave between the plates. However, if a wave guiding structure, such as a microstrip or ridge, is added between the PEC-PMC plates, a quasi-TEM mode is able to propagate along the guiding structure. Given the non-existence of PMC in nature, the metallic pins surface is applied to realize Artificial Magnetic Conductor (AMC) [10]. This novel gap waveguide has advantages compared to the microstrip line and the hollow waveguide. First of all, the gap waveguide can keep a planar profile as well as being low loss since the waves propagate in the air gap. Secondly, this technology can avoid the requirement of good metallic contacts between the parallel metallic plates because the metallic pins surface can create a high impedance to avoid the wave leakage. In addition, the gap waveguide makes fabrication process easy and cheap by molding or die-sink electrical discharge machining (EDM) technique. Furthermore, the AMC of gap waveguide technology can be utilized to package active components [11]-[12] and low-cost bandpass filters [13]-[14].

So far, there are four different realizations of gap waveguide technology - groove, ridge, inverted microstrip [8] and microstrip-ridge gap waveguides [15]. In [16]-[17] two highgain high-efficiency slot array antennas in V-band on ridge gap waveguide (RGW) have been reported. Other similar works on inverted microstrip gap waveguide (IMGW) have been reported in [18]-[19]. A planar array based on groove gap waveguide (GGW) has been reported in [20]. Recently, a novel wideband and continuous beam steering flat antenna on $\mathrm{RGW}$ is proposed in the $60-\mathrm{GHz}$ band [21]. A W-band high-gain L-probe excited substrate integrated cavity (SIC) antenna on RGW distribution networks is also proposed in [22]. In addition, a high-efficiency millimeter wave antenna array with the RGW feeding network is designed in [23]. 


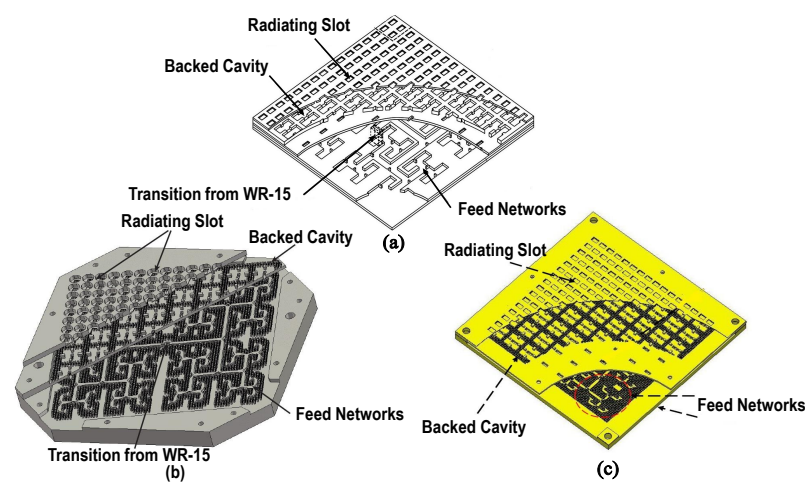

Fig. 1. (a) depicts a cavity-backed slot array antenna fed by hollow waveguide introduced in [4]. (b) shows a cavity-backed slot array antenna fed by ridge gap waveguide reported in [17] and a similar antenna fed by inverted microstrip gap waveguide stated in [18] is illustrated in (c). These three full corporate-feed antennas consist of three layers - distribution feed networks, backed cavity and radiation slots and their operating frequency all in the 60$\mathrm{GHz}$ band.

In order to achieve wideband and provide enough space for the distribution networks, all antennas in [4]-[7] and [16]-[23] have backed cavities where four slots are fed by one cavity. Therefore, such a type of antennas consist of three layers distribution feed networks, backed cavities and radiation slots. Some typical examples are shown in Fig. 1. Unfortunately, it is inevitable to increase the manufacture cost and design complexity for designing those corporate-feed antennas. On the other hand, instead of using the corporate-feed network, a series-feed network [24]-[26] is commonly applied for a single-layered fed slot array because its structure is simple. Nevertheless, its congenital disadvantage is also obvious. The bandwidth is usually limited to several percentage because of the long line effect. Thereafter, it is much preferred to have a slot array with single-layered corporate-feed network. A successful slot array with single-layered corporate-feed network can be found in [27] in the $60-\mathrm{GHz}$ using hollow waveguide manufactured by diffusion bonding technology. However, this manufacture technology is very expensive for massive production and its bandwidth is limited within $10 \%$. In [28] a $2 \times 2$ slot antenna unit cell based on ridge gap waveguide (RGW) in Ku-band was reported. This $2 \times 2$ unit cell utilizes bend parts in ridge line to excite slots and this geometry thereby has difficulties in layout of distribution network of a large array antenna.

In this paper, we initially introduce a new slot array antenna with single-layered corporate-feed network in the $60-\mathrm{GHz}$ band. This novel antenna avoids utilization of the backedcavities by a new layout of the corporate-feed distribution network in RGW and meanwhile achieves expected radiation pattern. The shape of the radiation slots is a modified doubleridge waveguide, which has a wider bandwidth than that of rectangular slots with a single-layered corporate-feed network.

The organization of this paper is as follows. Firstly, a novel slot unit cell is designed based on RGW, where the excitation scheme for the slot is different from those in [16][23]. Then the unit cell has been optimized in an infinite array environment in CST Microwave Studio for high directivity

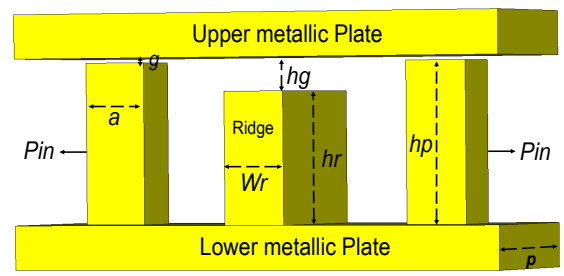

Fig. 2. The geometrical dimensions of the ridge gap waveguide for the array antenna in this work

and low reflection coefficient. Thereafter, a T-junction power divider including a transformer from a standard waveguide WR-15 to the ridged gap waveguide is designed for the input port of the whole array antenna. Finally, measurement results after fabrication are presented.

\section{GEOMETRICAL DIMENSIONS OF RGW FOR STOPBAND, TRANSITION AND MUTUAL COUPLING}

Based on the fundamental theory in [8], a gap waveguide supplies a stopband over a specific frequency range between the two parallel-plates. Since our target is to cover the whole unlicensed $60-\mathrm{GHz}$ frequency band $(57-66 \mathrm{GHz})$, the dimensions of the RGW should be properly chosen to cover as much of the $60-\mathrm{GHz}$ frequency band as possible. A simple geometrical schematic diagram of the RGW is depicted in Fig. 2. The dimensions of the pins and the ridge line are chosen according to the method introduced in [29]. A center frequency of $f_{0}=62 \mathrm{GHz}$ is assumed in this work. Then the height of the pins should be typically selected as $\lambda_{0} / 4$, which is equal to $1.2 \mathrm{~mm}$. Nevertheless, for the easier manufacture shorter pins have been chosen in this work. Furthermore, for achieving good radiation patterns the spacing between any two slots is selected as $4.2 \mathrm{~mm}$, which is equal to $0.87 \lambda_{0}$. Having considered the layout of the distribution network, four rows of metallic pins are required for the dimension of $4.2 \mathrm{~mm}$ and the corresponding periodicity of metallic pins is $1.05 \mathrm{~mm}$. On the other hand, the width of square metallic pins is chosen as $0.4 \mathrm{~mm}$. Thereby, the spacing between two arbitrary pins is $0.65 \mathrm{~mm}$, which is equal to the difference of two mentioned variables. The dispersion diagram of the ridge gap waveguide is depicted in Fig. 3. The stopband is from 38 to $125 \mathrm{GHz}$, which covers the whole V-band.

In corporate-feed array antennas in [16]-[23], the space for the layout of ridge lines is usually very limited so that the backed cavities is applied to provide more space for the

TABLE I

Design PARAmeters of THE StRUCTURE IN Fig. 1

\begin{tabular}{cc}
\hline \hline Height of the Ridge $\left[h_{r}\right]$ & $0.75 \mathrm{~mm}$ \\
\hline Width of the Ridge $\left[W_{r}\right]$ & $0.55 \mathrm{~mm}$ \\
\hline Height of the Air Gap between Pins and upper Plate $[g]$ & $0.03 \mathrm{~mm}$ \\
\hline Height of Air Gap between Ridge and upper Plate $\left[h_{g}\right]$ & $0.2 \mathrm{~mm}$ \\
\hline Height of the Pin $\left[h_{p}\right]$ & $0.92 \mathrm{~mm}$ \\
\hline Width of the Pin $[a]$ & $0.4 \mathrm{~mm}$ \\
\hline Period of the Pin $[p]$ & $1.05 \mathrm{~mm}$ \\
\hline \hline
\end{tabular}




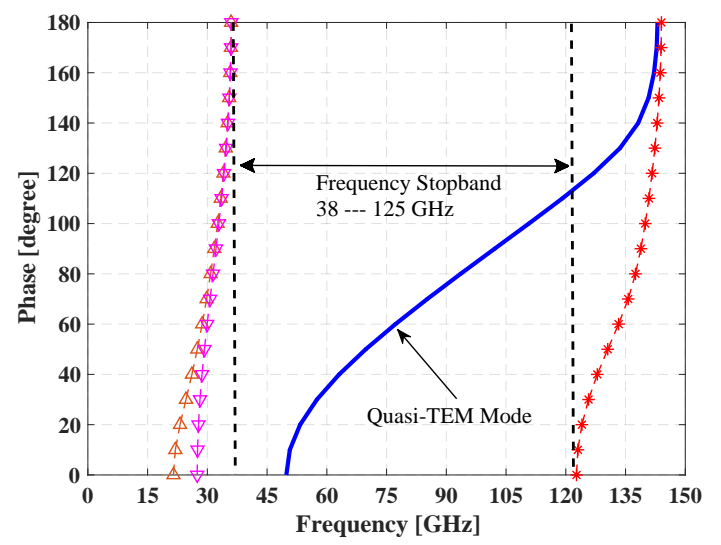

Fig. 3. Corresponding dispersion diagram of the ridge gap waveguide depicted in Fig. 1. The blue solid line stands for the Quasi-TEM mode.

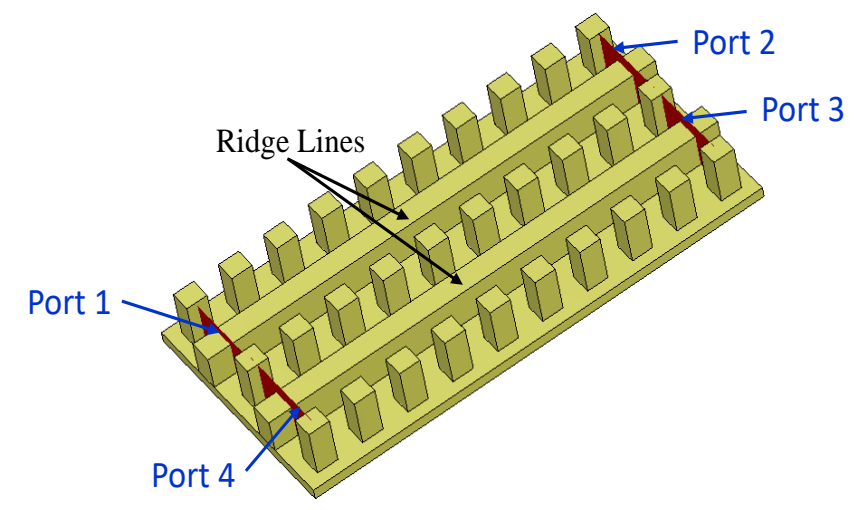

Fig. 4. Top view of two parallel ridge lines with one row of pins in between. Upper flat metallic plate is hidden to illustrate the bottom plate.

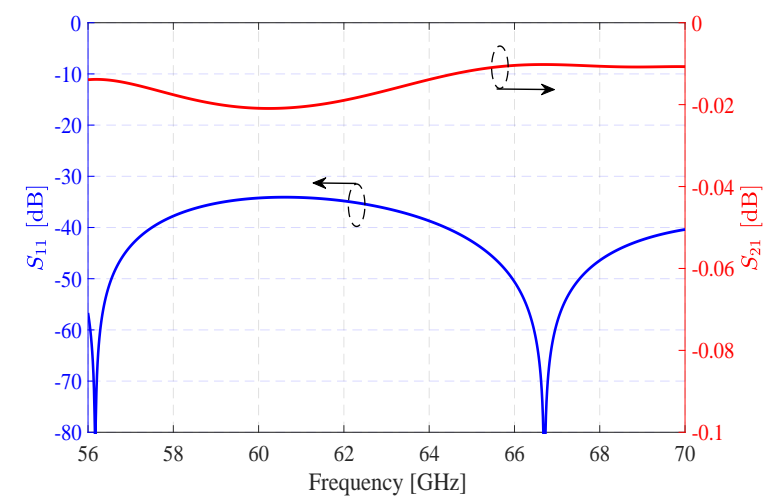

Fig. 5. Simulated reflection coefficient and the transmission coefficient of the two parallel RGWs in Fig. 4.

distribution feed network. Therefore, it is a big challenge to lay out feed networks without backed cavities in this work. Before designing the whole array antenna, the coupling between two ridge lines with only one row of pins should be tested. Fig.

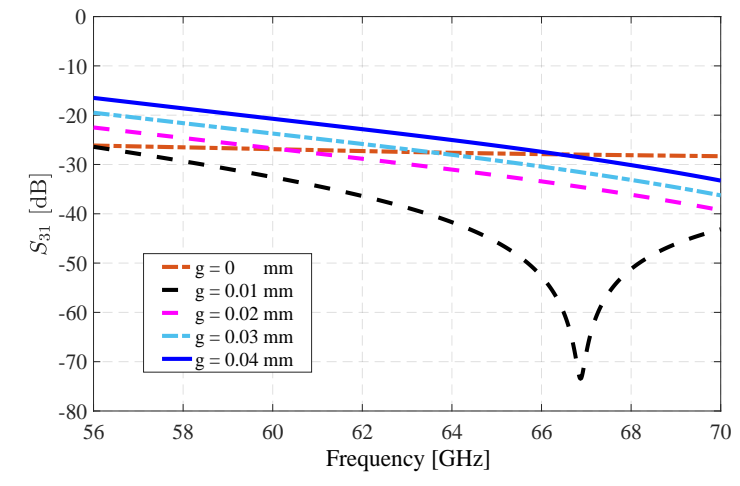

Fig. 6. Mutual coupling investigation on one row pins between two straight ridge lines defined in Fig. 4. Parameter sweep for $g$ is carried out in CST Microwave Studio.

4 illustrates a simple model to examine the performance. The length of the whole structure is $10.5 \mathrm{~mm}$. While the height of the metallic pins $h_{p}$ is already fixed, we have to search for the optimal dimensions of air gap height $g$, the width $W_{r}$ and the height $h_{r}$ of the ridge in order to minimize the reflection coefficients and the coupling $S_{31}$ between two ridge lines with only one row of pins. As illustrated in Fig. 5, the reflection coefficient of the straight ridge line is below $-33 \mathrm{~dB}$ from 56 to $70 \mathrm{GHz}$. This outcome is acceptable for the array antenna design in this work. The parameter sweep method is also utilized for $g$ stated in Fig. 2 in this part in order to minimize the mutual coupling between the two ridge lines. As is shown in Fig. 6, the mutual coupling is lower than $-20 \mathrm{~dB}$ when the air gap between the metallic pins and upper metallic plate $g$ is smaller than $0.03 \mathrm{~mm}$. This value is acceptable for designing distribution feed network based on RGW only with one row of pins [17]. Having considered the requirement of non-electrical contact, we have selected $0.03 \mathrm{~mm}$ in this work and it presents that the feed network has very low leakage and mutual coupling between two neighbor ridge lines with one row of pins in the $60-\mathrm{GHz}$ band.

\section{Design of Antenna Unit Cell}

As depicted in Fig. 7, the antenna unit cell consists of a radiating slot and a ridge feeding line. This element is under periodic boundary condition defined in CST Microwave Studio. The slot in this work is designed as an ' 8 ' shape, which is actually a double ridge slot with circularly curved corners and smoothly profiled ridges. The double ridges will lower the cutoff frequency of the dominant mode and will raise the cutoff frequency of the next higher order modes in the slot [30]. Therefore, it increases the bandwidth of the array antenna compared with that by using a normal rectangular slots. To excite the electromagnetic wave in the slot, the magnetic field created by the ridge line of feed layer should rotate along the vertical direction of the double ridged slot. Then electromagnetic wave can radiate with same phase and polarization from slot. This method is actually a magnetic coupling radiation, which is different from excitation method stated in [16]-[20] 


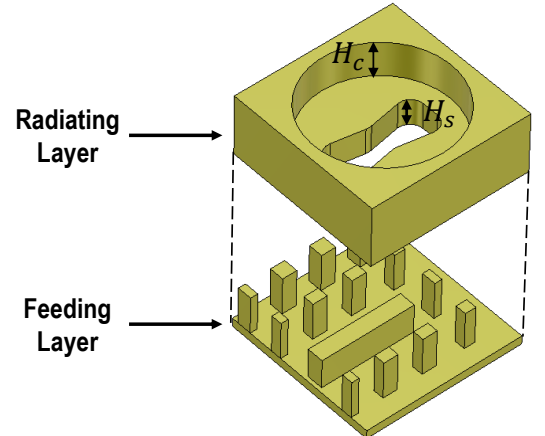

(a)

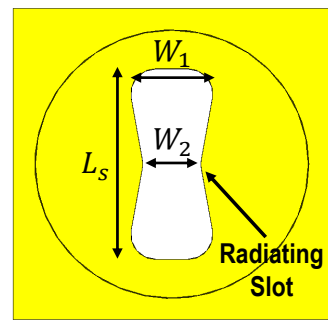

(b)

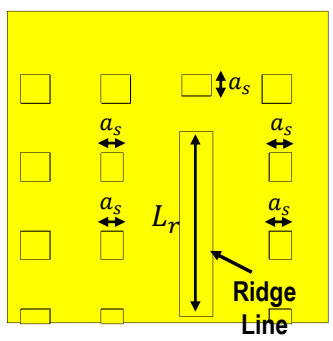

(c)
Fig. 7. Proposed antenna unit cell: (a) Exploded view. (b) Radiating layer. (c) Feeding layer.

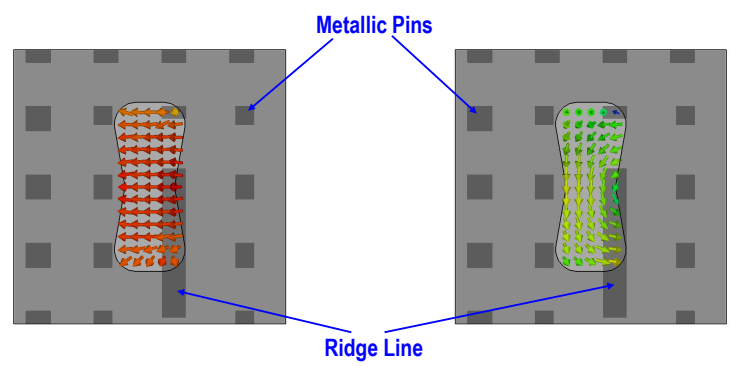

(a)

(b)
Fig. 8. Illustrations for field-distributions: (a) E-filed. (b) H-field.

and [28]. It avoids utilization of the conventional bend ridge line and makes the feed network very compact so the layout of the feed network is possible in such limited space as in the single-layered corporate-feed network case. The length of the slot $L_{s}$ is firstly chosen so that the mutual coupling to the neighbor feed line can be eliminated. If $L_{s}$ is small, the slot would not extend to the neighbor ridge feed line. $W_{1}$, $W_{2}, H_{s}$ and $L_{r}$ have been optimized to achieve the minimum

TABLE II

Design Parameters of The Structure in Fig. 6

\begin{tabular}{cc}
\hline \hline Width of the Slot $\left[W_{1}\right]$ & $1.13 \mathrm{~mm}$ \\
\hline Width of the Slot $\left[W_{2}\right]$ & $0.8 \mathrm{~mm}$ \\
\hline Length of the Slot $\left[L_{s}\right]$ & $2.7 \mathrm{~mm}$ \\
\hline Length of the Ridge $\left[L_{r}\right]$ & $1.8 \mathrm{~mm}$ \\
\hline Width of the smaller Pin $\left[a_{s}\right]$ & $0.3 \mathrm{~mm}$ \\
\hline Height of the Slot $\left[H_{s}\right]$ & $0.75 \mathrm{~mm}$ \\
\hline Height of the Circular Cavity $\left[H_{c}\right]$ & $1.25 \mathrm{~mm}$ \\
\hline \hline
\end{tabular}

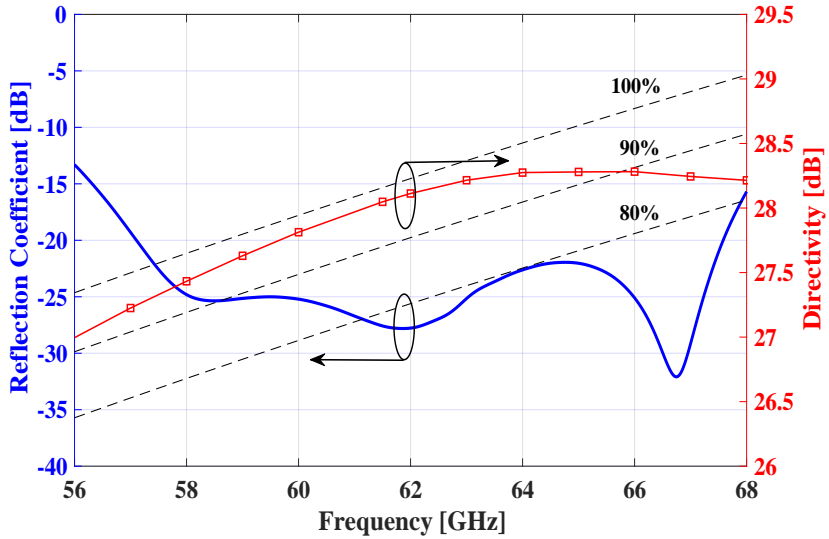

Fig. 9. Simulated reflection coefficient of the single slot unit cell and directivity of an array antenna with $8 \times 8$ slot aperture dimension in infinite array environment.

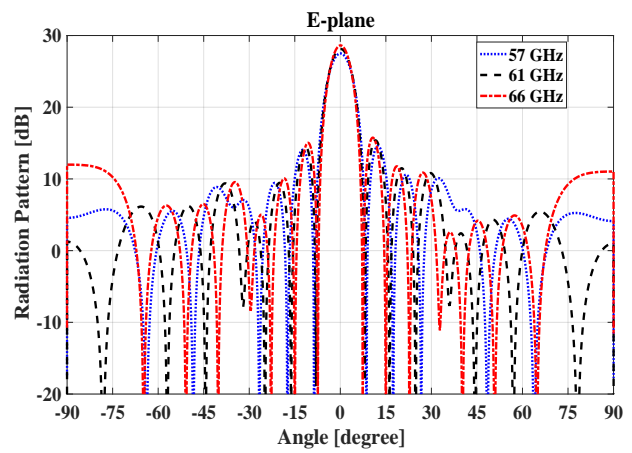

Fig. 10. E-plane radiation pattern of the $8 \times 8$-element array antenna with periodic boundary condition.

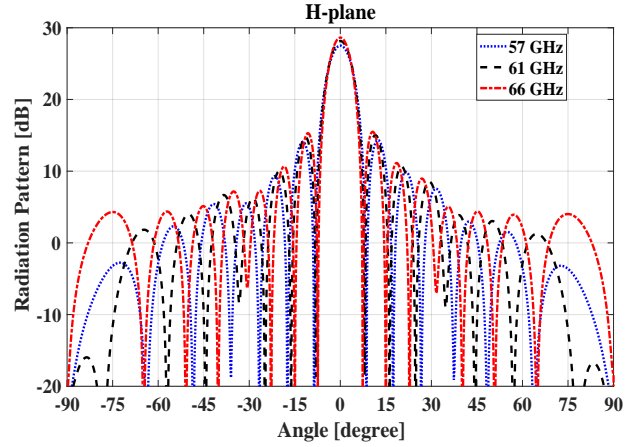

Fig. 11. H-plane radiation pattern of the $8 \times 8$-element array antenna with periodic boundary condition.

reflection coefficient. TABLE II lists the optimized geometrical parameters of the unit cell shown in Fig. 7. Fig. 8 depicts the corresponding $\mathrm{E}$ - and $\mathrm{H}$-fields distributions in the double ridged slot from CST Microwave Studio. The magnetic field is desired as predicted before. The distance between any two slots is equal to $0.87 \lambda_{0}$, which satisfies the condition 


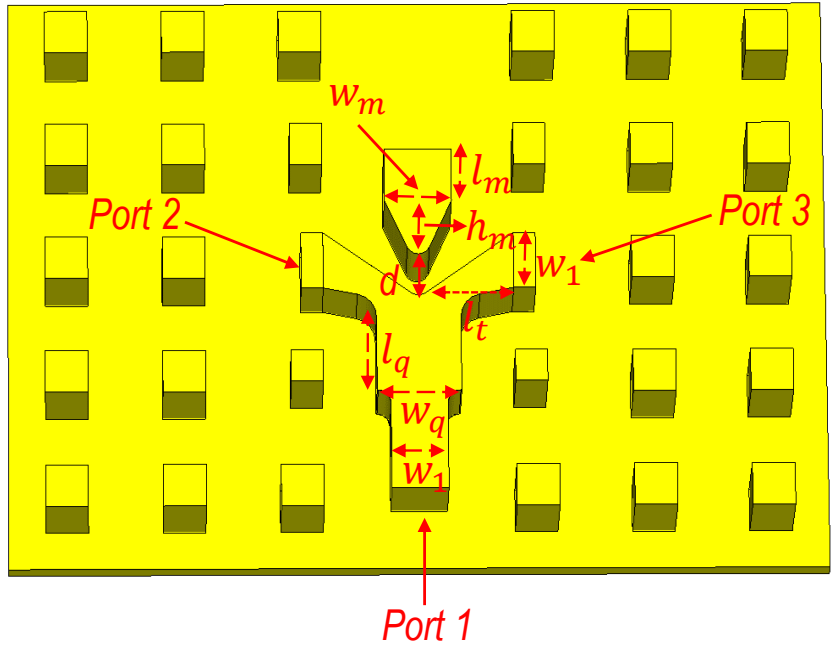

Fig. 12. Geometry of the T-junction power divider based on RGW in this work. The upper metallic plate is hidden.

TABLE III

Design Parameters of THE Structure IN Fig. 12

\begin{tabular}{cc}
\hline \hline$w_{1}$ & $0.54 \mathrm{~mm}$ \\
\hline$w_{q}$ & $0.8 \mathrm{~mm}$ \\
\hline$l_{q}$ & $0.72 \mathrm{~mm}$ \\
\hline$l_{t}$ & $0.92 \mathrm{~mm}$ \\
\hline$d$ & $0.4 \mathrm{~mm}$ \\
\hline$w_{m}$ & $0.72 \mathrm{~mm}$ \\
\hline$l_{m}$ & $0.6 \mathrm{~mm}$ \\
\hline$h_{m}$ & $0.47 \mathrm{~mm}$ \\
\hline \hline
\end{tabular}

of non-grating lobes (element spacing $\mathrm{d}<1 /(1+1 / 8) \lambda_{0}=0.89 \lambda_{0}$ ) in both E- and H-planes [31]. Fig. 9 shows corresponding reflection coefficient of the unit cell and the directivity of $8 \times 8$ element array antenna in infinite array environment. It has $20 \%$ impedance bandwidth (over 56-68 GHz) with input reflection coefficient better than $-15 \mathrm{~dB}$. The directivity is higher than $27.5 \mathrm{dBi}$ and the aperture efficiency is better than $90 \%$ from 56 to $66 \mathrm{GHz}$. Here we have utilized the CST Microwave Studio periodic boundary condition along the lateral and longitudinal directions of $8 \times 8$-element in order to estimate the radiation pattern of the whole structure. Fig. 10 and 11 illustrate the radiation patterns in both $\mathrm{E}$ - and $\mathrm{H}$-planes of $8 \times 8$-element slot array antenna.

\section{Corporate-Feed Network Design}

The corporate-feed array antenna utilizes a T-junction power divider to feed each unit cell in the whole array antenna. The configuration of the T-junction RGW power divider used in this work is depicted in Fig. 12. In TABLE III, the geometrical parameters of the T-junction RGW power divider are listed. The corresponding simulated reflection coefficient is shown in Fig. 13, which is below $-30 \mathrm{~dB}$ from 57 to $66 \mathrm{GHz}$. In order to have an easy massive production of the antenna by using molding technique of plastic material with metalized surface treatment, the smallest dimensions of the extruding parts (pins and ridges) are $0.4 \mathrm{~mm}$.

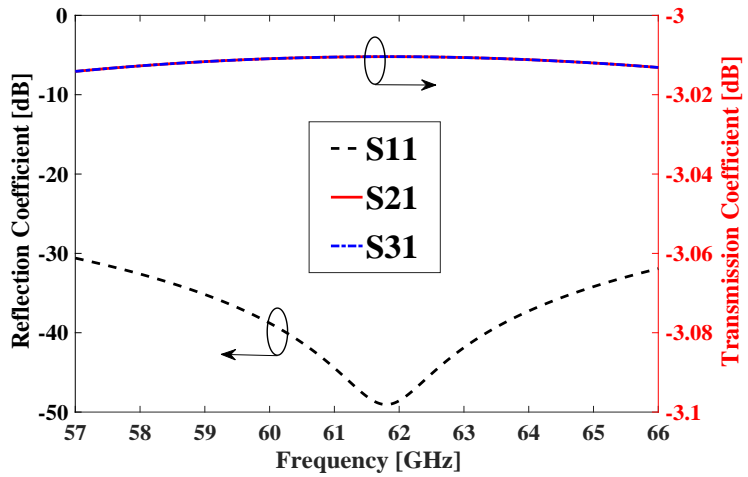

Fig. 13. Simulated reflection coefficient and transmission coefficient of the power divider in Fig. 12.

The whole array antenna in this work is excited through a standard V-band rectangular waveguide (WR-15) at the bottom of whole structure. In this work we prefer a hybrid power divider similar as that described in [17]-[19]. The hybrid structure is illustrated in Fig. 14. The simulated S-parameters of the structure both in amplitude and phase are shown in Fig. 15. The reflection coefficient $S_{11}$ in the whole band $56-68$ $\mathrm{GHz}$ is below $-20 \mathrm{~dB}$. In addition, we should point out that the phases of the output ports have 180 degree difference, as shown in Fig. 15 (b). Fig. 16 shows the whole array antenna. The complete corporate-feed network consists of two 16-way

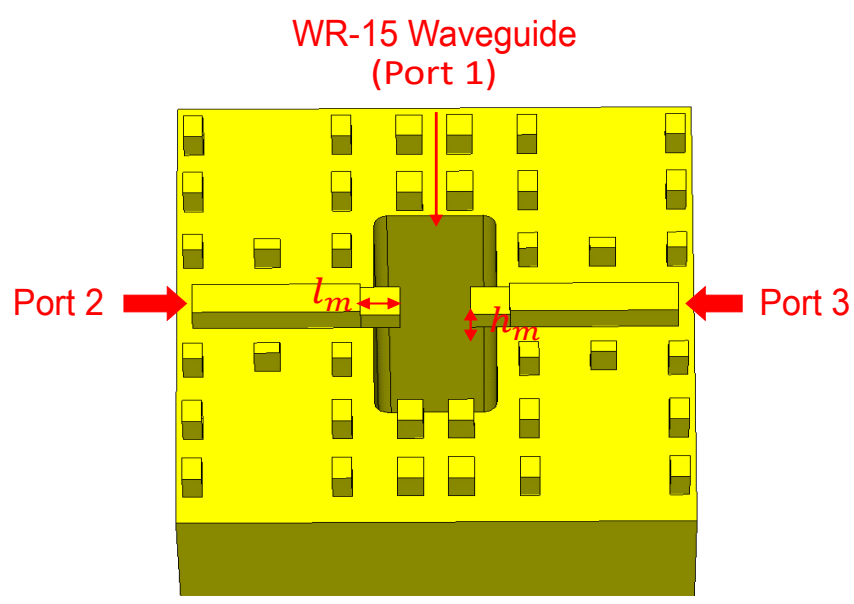

Fig. 14. Geometrical illustration for hybrid transition from WR-15 to RGW $l_{m}=0.75 \mathrm{~mm}$ and $h_{m}=0.45 \mathrm{~mm}$.

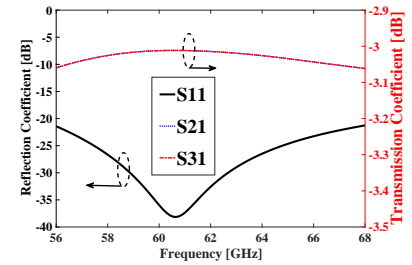

(a)

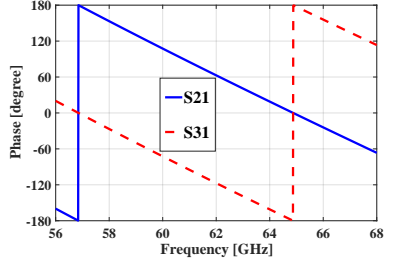

(b)
Fig. 15. Simulated S-parameter results of designed hybrid transition from WR-15 to RGW. (a) Amplitude. (b) Phase. 


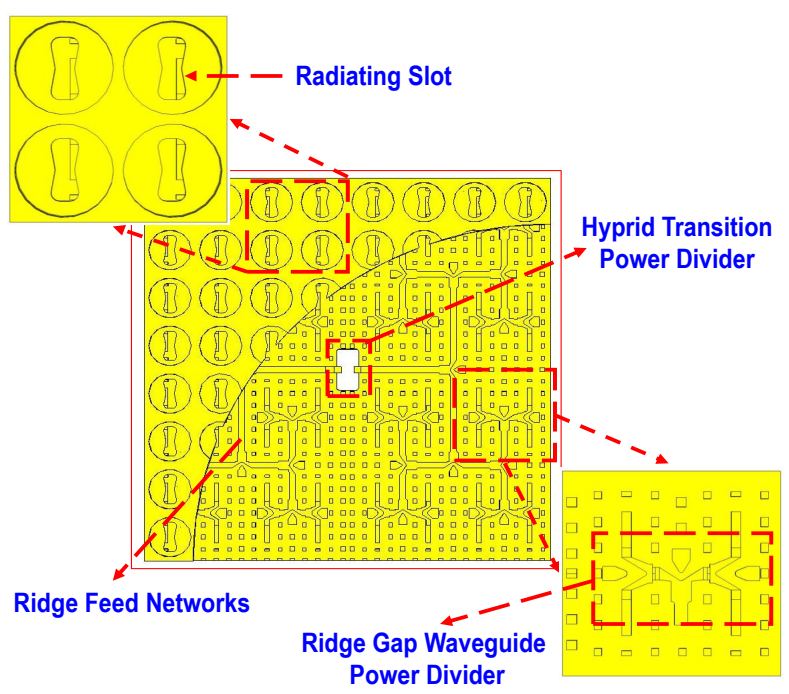

Fig. 16. Proposed single-layered corporate-feed $8 \times 8$ slot array antenna.

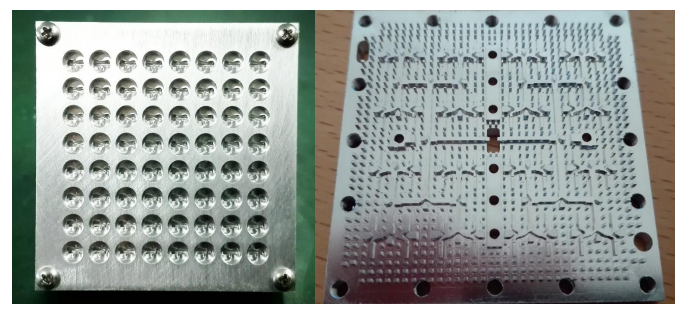

Fig. 17. Configuration of the $8 \times 8$ slot array and photos of the fabricated antenna.

RGW power dividers from central hybrid transition power divider to 64 radiating slots. The two 16-way feed networks are mirrored since the phase difference from hybrid transition part is able to be compensated. The thickness of the whole array antenna is $9.7 \mathrm{~mm}$.

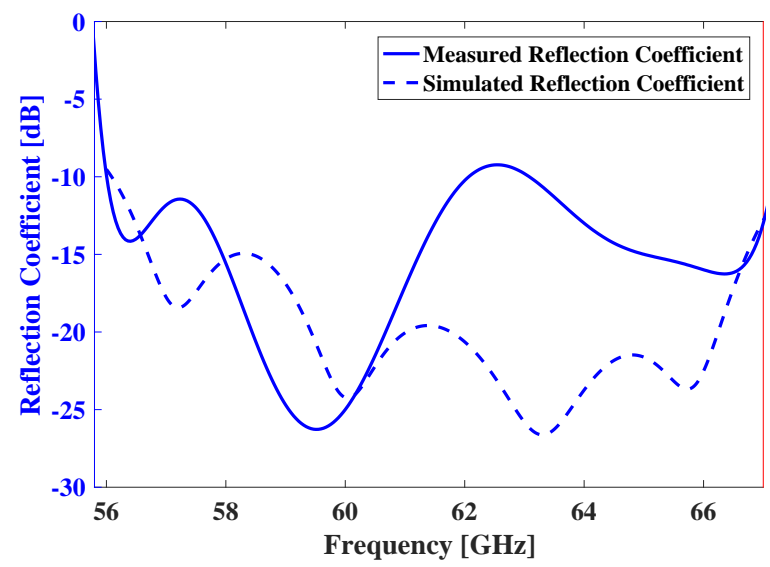

Fig. 18. The simulated and the measured reflection coefficients of the proposed array antenna.

\section{EXPERIMENTAL RESULTS}

The fabricated $8 \times 8$ slot array antenna is illustrated in Fig. 17. The prototype is manufactured by Computerized Numerical Control (CNC) technology with aluminium (with electric conductivity $3.6 \times 10^{7} \mathrm{~S} / \mathrm{m}$ ). Planar dimension of the proposed antenna is $36 \mathrm{~mm} \times 36 \mathrm{~mm}$ (The dimensions of effective aperture are $33.6 \mathrm{~mm} \times 33.6 \mathrm{~mm}$ ).

The entire structure is simulated in CST Microwave Studio. Since the hybrid transition, T-junction power divider and unit cell already have excellent reflection coefficients, the simulated reflection coefficient of complete antenna is below $-15 \mathrm{~dB}$ from 57 to $66 \mathrm{GHz}$ without any further optimization, as shown in Fig. 18. However, the measured reflection coefficient is a bit higher than simulated one because the assembly tolerance of the proposed antenna is around $0.015 \mathrm{~mm}$, which is measured by a X-ray inspection machine of Nikon, XTH 160 with a measurement tolerance of $20 \mathrm{~nm}$.

The radiation patterns and the gain were measured in an anechoic chamber in China Academy of Space Technology in Shanghai. The simulated and the measured far-field radiation

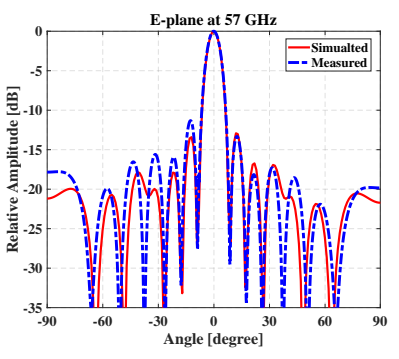

(a)

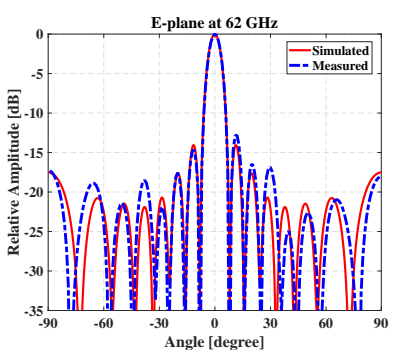

(c)

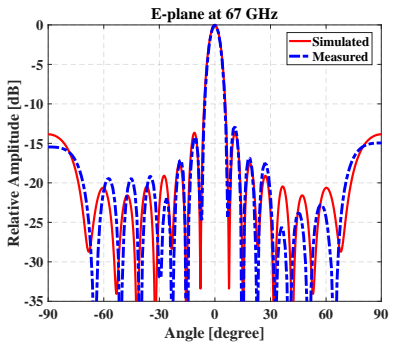

(e)

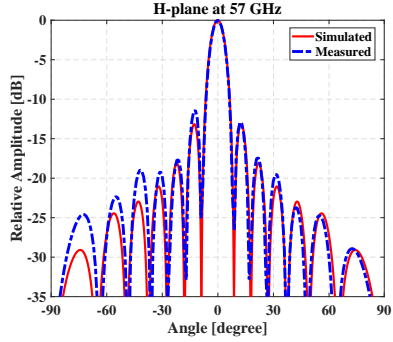

(b)

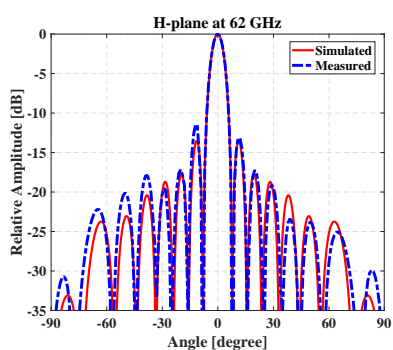

(d)

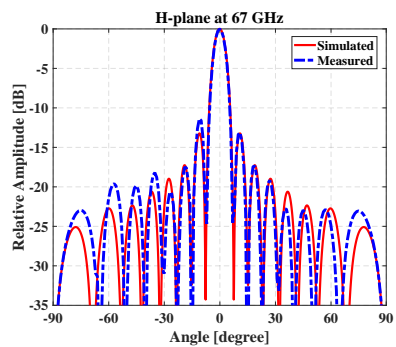

(f)
Fig. 19. The simulated and the measured radiation patterns of proposed array antenna on both E-plane and H-plane at $57 \mathrm{GHz}, 62 \mathrm{GHz}$ and $67 \mathrm{GHz}$. 
TABLE IV

COMPARISON BETWEEN THE PROPOSED AND REPORTED 60-GHZ PLANAR ANTENNA ARRAYS

\begin{tabular}{|c|c|c|c|c|c|c|c|c|}
\hline Performance & Ref.[4] & Ref.[5] & Ref.[6] & Ref.[17] & Ref.[18] & Ref.[20] & Ref.[27] & Present Work \\
\hline Technology & Hollow Waveguide & Microstrip & SIW & RGW & IMGW & GGW & Hollow Waveguide & RGW \\
\hline Size $[\mathrm{cm}]$ & $7.6 \times 7.5$ & $24 \times 24$ & $1.6 \times 1.7$ & $6.4 \times 6.4$ & $6.4 \times 6.4$ & $7.7 \times 7.2$ & $6.8 \times 6.7$ & $3.36 \times 3.36$ \\
\hline Number of Elements & 256 & 4096 & 16 & 256 & 256 & 256 & 256 & 64 \\
\hline Number of Layers & 3 & 3 & 4 & 3 & 3 & 3 & 2 & 2 \\
\hline Frequency Band [GHz] & $57-65$ & $58-67$ & $54-68$ & $57-68$ & $54.5-64$ & $55.5-67$ & $59-64$ & $56.5-67$ \\
\hline Bandwidth $[\mathrm{S} 11<-10 \mathrm{~dB}]$ & $13 \%$ & $12 \%$ & $22 \%$ & $19 \%$ & $17 \%$ & $19 \%$ & $8 \%$ & $17 \%$ \\
\hline Max Gain [dBi] & 33 & 39 & 18 & 32 & 30.5 & 32.5 & 32.5 & 27 \\
\hline Antenna Efficiency & $80 \%-85 \%$ & $15 \%-20 \%$ & $35 \%-45 \%$ & $60 \%-70 \%$ & $40 \%-60 \%$ & $75 \%-85 \%$ & $70 \%-75 \%$ & $70 \%-85 \%$ \\
\hline
\end{tabular}

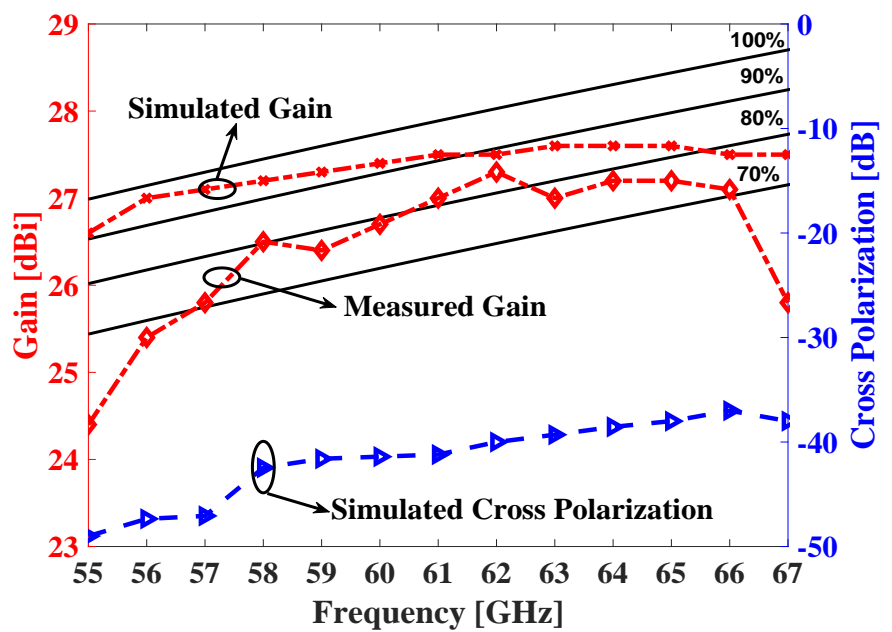

Fig. 20. Red lines: simulated and measured gains of the proposed array antenna. Blue line: simulated cross-polarized value.

patterns of proposed antenna at 57, 62 and $67 \mathrm{GHz}$ in both Eand H-planes are depicted in Fig. 19. The measured radiation patterns show a good agreement with the simulated results. The simulated and the measured radiation patterns are symmetrical, and the first relative side-lobe levels in both E- and $\mathrm{H}$-planes are around $-12 \mathrm{~dB}$. These mean that the distribution network works very well with low mutual couplings among the ridge feed lines. Since the element spacing of proposed antenna is $4.2 \mathrm{~mm}$ and wavelength at $67 \mathrm{GHz}$ is equal to $4.477 \mathrm{~mm}$, so the ratio $4.2 / 4.477=0.94$, which is larger than the non-grating lobes condition of 0.89 at $67 \mathrm{GHz}$ [31], the radiation patterns in E-plane at $67 \mathrm{GHz}$ at \pm 90 degree are higher than the desired.

The measured and the simulated antenna gains are shown in Fig. 20. It can be observed that the realized gain varies from 25.8 to $27 \mathrm{dBi}$ over 57 to $66 \mathrm{GHz}$, whereas the antenna efficiency is more than $70 \%$ (Here the definition of antenna efficiency is defined as $e_{a n t}=e_{r a d} \cdot e_{p o l} \cdot e_{a p}$, where $e_{r a d}, e_{p o l}$ and $e_{a p}$ are radiation efficiency, polarization efficiency and aperture efficiency, respectively). The simulated relative crosspolarization values are below $-37 \mathrm{~dB}$ from 56 to $67 \mathrm{GHz}$, as also seen in Fig. 20.

In table IV fundamental characteristics and performances of different kinds of $60-\mathrm{GHz}$ antenna arrays are listed to compare with our work. For the antennas by using conventional microstrip, the high loss and the radiation leakage are the critical issues when designing large microstrip corporate-feed networks for array antenna in mmWs such as the one in [5] where the antenna efficiency is only $15 \%$ - 20\%. The SIW technology also has applied the substrate to integrate with active components. Thereby, it still has high dielectric loss in mmWs. Probably utilization of low loss substrate materials is an opportunity to fabricate SIW prototypes, but such solution might increase the cost. Another transmission line including substrate materials is IMGW. However, it cannot totally avoid the dielectric loss and thereby the antenna efficiency of a large array reported in [18] is also limited within 60\%. Without utilization the substrate materials, the GGW, the hollow waveguide and the RGW thereby have a huge competitive strength. Nevertheless, the GGW and the RGW still have two advantages among them. Firstly, in [4] and [27] laminated plate technology has been applied for fabrication and their cost is very expensive. Secondly, the bandwidth of the array antennas by hollow waveguide is somehow limited. On the other hand, the GGW and the RGW also sometimes have the disadvantage of expensive fabrication. However, suitable parameters for metallic pins will reduce the fabrication cost. In this work, we have realized a two-layer slot array antenna which still possesses the equal performances of other three-layer antennas in [4] and [20]. Meanwhile it reduces the fabrication cost and thereby will be very helpful for industry.

\section{CONCLUSION}

A single-layered corporate-feed array antenna based on RGW at $60-\mathrm{GHz}$ is presented. This array antenna not only overcomes the disadvantage of narrow bandwidth from conventional single layer array with series-fed network, but also realize the advantage of wideband from three-layer slot array with backed cavity. The simpler geometry will definitely decrease the manufacture cost so that it has huge commercial potential in the future. The array antenna can be directly connected with standard WR-15 interface. An $8 \times 8$-element slot array has been designed, simulated, manufactured and measured. The measured gain is higher than $26 \mathrm{dBi}$ from 58 to $66 \mathrm{GHz}$, correspondingly the antenna efficiency larger than $70 \%$. 


\section{ACKNOWLEDGMENT}

The authors would like to thank Prof.Dr.Per-Simon Kildal for his sincere support during this work. Before this work finished he unexpectedly passed away. Many of the ideas have been discussed with him. The work has been supported by the European Research Council (ERC) via an advanced investigator grant ERC-2012-ADG 20120216, and by the VINNOVA smart electronics program with the project grant 2015-01387.

\section{REFERENCES}

[1] P. Smulders, "Exploring the $60 \mathrm{GHz}$ band for local wireless multimedia access: Prospects and future directions," IEEE Commun. Mag., vol. 40, no. 1 , pp. 40-147, Jan. 2002

[2] T. S. Rappaport, J. N. Murdck, and F. Gutierrez, "State of the art in 60GHz integrated circuits and systems for wireless communications," Proc. IEEE, vol. 99, no. 8, pp. 1390-1436, Aug. 2011.

[3] J. H. Van Vleck, "The absorption of microswaves by oxygen," Phys. Rev., vol. 71, no. 7, pp. 413-424, 1947.

[4] Y. Miura, J. Hirokawa, M. Ando, Y. Shibuya and G. Yoshida, "Double layer full-corporate-feed hollow-waveguide slot array antenna in the 60 GHz band," IEEE Trans. Antennas Propag., vol. 59, no. 8, pp. 2844-2851, Aug. 2011

[5] J. Wu, Y. J. Cheng, and Y. Fan, "A wideband high-gain high-efficiency hybrid integrated plate array antenna for V-Band inter-satellite links," IEEE Trans. Antennas Propag., vol. 63, no. 4, pp. 1225-1233, Apr. 2015.

[6] Y. Li and K.-M. Luk, "Low-cost high-gain and broadband substrate integrated-waveguide-fed patch antenna array for $60-\mathrm{GHz}$ band," IEEE Trans. Antennas Propag., vol. 62, no. 11, pp. 5531-5538, Nov. 2014

[7] Y. Li and K.-M. Luk, "60-GHz substrate integrated waveguide fed cavitybacked aperture-coupled microstrip patch antenna arrays," IEEE Trans. Antennas Propag., vol. 63, no. 3, pp. 1075-1085, Mar. 2015.

[8] P.-S. Kildal, "Three metamaterial-based gap waveguides between parallel metal plates for $\mathrm{mm} / \mathrm{submm}$ waves," in 3rd European Conference on Antennas and Propagation, EuCAP 2009, pp. 28-32, Mar. 2009.

[9] A. U. Zaman and P.-S. Kildal, "Gap waveguides," in Handbook of Antenna Technologies, Z. N. Chen, D. Liu, H. Nakano, X. Qing, and T. Zwick, Eds. Singapore: Springer, pp. 3273-3347, 2016.

[10] P.-S. Kildal, "Artificially soft and hard surfaces in electromagnetics," IEEE Trans. Antennas Propag., vol. 28, no. 10, pp. 1537-1544, Oct. 1990.

[11] A. U. Zaman, M. Alexanderson, T. Vukusic and P.-S. Kildal, "Gap waveguide PMC packaging for improved isolation of circuit components in high-frequency microwave modules," IEEE Trans. Compon. Packag. Manuf. Technol., vol. 4, no. 1, pp. 16-25, Jan. 2014.

[12] E. Rajo-Iglesias, P. S. Kildal, A. U. Zaman, and A. Kishk, "Bed of springs for packaging of microstrip circuits in the microwave frequency range," IEEE Trans. Compon. Packag. Manuf. Technol., vol. 2, no. 7, pp. 1623-1628, Jul. 2012.

[13] A. U. Zaman, P.-S. Kildal and A. A. Kishk, "Narrow-Band microwave filter using high-Q groove gap waveguide resonators with manufacturing flexibility and no sidewalls," IEEE Trans. Compon. Packag. Manuf. Technol., vol. 2, no. 11, pp. 1882-1889, Nov. 2012.

[14] A. Vosoogh, A. A. Brazalez and P.-S. Kildal, "A V-Band inverted microstrip gap waveguide end-coupled bandpass filter, "IEEE Antennas Wireless Propag. Lett., vol. 26, no. 4, pp. 261-263, Apr. 2016.

[15] H. Raza, J. Yang, P.-S. Kildal, and E. A. Als, "Microstrip-ridge gap waveguideStudy of losses, bends, and transition to WR-15," IEEE Trans. Microw. Theory Techn., vol. 62, no. 9, pp. 1943-1952, Sept. 2014.
[16] A. Vosoogh, and P.-S. Kildal, "Corporate-Fed planar $60 \mathrm{GHz}$ slot array made of three unconnected metal layers using AMC pin surface for the gap waveguide," IEEE Antennas Wireless Propag. Lett., pp. 1935-1938, Dec. 2015.

[17] A. Vosoogh, P.-S. Kildal and V. Vassilev, "Wideband and high-gain corporate-fed gap waveguide slot array antenna with ETSI class II radiation pattern in V-Band," IEEE Trans. Antennas Propag., vol. 65, no. 4, pp. 1823-1831, Apr. 2017.

[18] J. Liu, A. Vosoogh, A. U. Zaman and J. Yang, "Design and fabrication of a high gain $60-\mathrm{GHz}$ cavity-backed slot antenna array fed by inverted microstrip gap waveguide," IEEE Trans. Antennas Propag., vol. 65, no. 4, pp. 2117-2122, Apr. 2017.

[19] J. Liu, A. Vosoogh, A. U. Zaman and P.-S. Kildal, "Design of $8 \times 8$ slot array antenna based on inverted microstrip gap waveguide," Antennas and Propagation (ISAP), 2016 International Symposium on, pp. 760-761, Oct. 2016

[20] A. Farahbakhsh, D. Zarifi and A. U. Zaman, "60-GHz groove gap waveguide based wideband $\mathrm{H}$-plane power dividers and transitions: for use in high-gain slot array antenna," IEEE Trans. Microw. Theory Techn., vol. 65 , no. 11, pp. 4111-4121, Nov. 2017.

[21] K. Tekkouk, J. Hirokawa, R. Sauleau and M. Ando, "Wideband and large coverage continuous beam steering antenna in the 60-GHz band," IEEE Trans. Antennas Propag., vol. 65, no. 9, pp. 4418-4426, Sept. 2017.

[22] B. Cao, H. Wang, Y. Huang and J. Zheng, "High-gain L-probe excited substrate integrated cavity antenna array with LTCC-based gap waveguide feeding network for W-Band application," IEEE Trans. Antennas Propag., vol. 63, no. 12, pp. 5465-5474, Dec. 2015.

[23] M. S. Sorkherizi, A. Dadgarpour and A. A. Kishk, "Planar highefficiency antenna array using new printed ridge gap waveguide technology," IEEE Trans. Antennas Propag., vol. 65, no. 7, pp. 3772-3776, Jul. 2017.

[24] S. Park, Y. Tsunemitsu, J. Hirokawa and M. Ando, "Center feed single layer slotted waveguide array," IEEE Trans. Antennas Propag., vol. 54, no. 5, pp. 1474-1480, May. 2006.

[25] M. Ando, J. Hirokawa, T. Yamamoto, A. Akiyama, Y. Kimura and N. Goto, "Novel single-layer waveguides for high-efficiency millimeter-wave arrays," IEEE Trans. Microw. Theory Techn., vol. 46, no. 6, pp. 792-799, Jun. 1998.

[26] Y. Tsunemitsu, S. Matsumoto, Y. Kazama, J. Hirokawa, and M. Ando, "Reduction of aperture blockage in the center-feed alternatingphase fed single-layer slotted waveguide array antenna by E- to H-plane cross-junction power dividers," IEEE Trans. Antennas Propag., vol. 56, no. 6, pp. 1787-1790, Jun. 2008

[27] M. Sano, J. Hirokawa, and M. Ando, "Single-layer corporate-feed slot array in the $60-\mathrm{GHz}$ band using hollow rectangular coaxial lines," IEEE Trans. Antennas Propag., vol. 62, no. 10, pp. 5068-5076, Oct. 2014.

[28] A. U. Zaman and P.-S. Kildal, "Wide-band slot antenna arrays with single-layer corporate-feed network in ridge gap waveguide technology," IEEE Trans. Antennas Propag., vol. 62, no. 6, pp. 2992-3001, Jun. 2014

[29] E. Rajo-Iglesias and P.-S. Kildal, "Numerical studies of bandwidth of parallel-plate cut-off realized by a bed of nails, corrugations and mushroom-type electromagnetic bandgap for use in gap waveguides," IET Microw.Antennas Propag., vol. 5, no. 3, pp. 282-289, Feb. 2011.

[30] S. Hopfer, "The design of ridged waveguides," IRE Transaction on Microwave Theory and Techniques, vol. 3, no. 5, pp. 20-29, Oct. 1955. 